\title{
Políticas de educação bilíngue para estudantes surdos: contribuições ao letramento acadêmico no ensino superior
}

\section{Bilingual education policies for deaf students: contributions to academic literacy in higher education}

\author{
Sueli Fernandes* \\ Laura Ceretta Moreira*
}

\begin{abstract}
RESUMO
O ingresso progressivo de estudantes surdos ao ensino superior, na última década, demandou mudanças institucionais importantes quanto ao direito à educação bilíngue, ou seja, oportunizar acesso e produção de conhecimento em Língua Brasileira de Sinais (Libras) e em Língua Portuguesa na modalidade escrita. Nesse sentido, este artigo tem como objetivo discutir o processo de educação bilíngue de estudantes surdos no ensino superior, apresentando ações desenvolvidas no âmbito da Universidade Federal do Paraná (UFPR), com destaque às contribuições trazidas ao processo de letramento acadêmico bilíngue nos cursos de graduação e pós-graduação. Entendemos que a centralidade, atribuída à figura do tradutor intérprete de Libras e ao atendimento educacional especializado na política nacional de educação inclusiva, não responde às necessidades dos estudantes surdos adultos trabalhadores que chegam ao ensino superior, com dificuldades na leitura e escrita do português e experiências pouco significativas em língua de sinais. Como resultados positivos, apontamos as contribuições ao letramento acadêmico bilíngue de estudantes surdos, o desenvolvimento de metodologia específica para elaboração de materiais bilíngues - em diferentes gêneros textuais - e a ampliação dos referenciais de atuação do tradutor-intérprete no processo de inclusão. O processo inclusivo se constitui
\end{abstract}

DOI: $10.1590 / 0104-4060.51048$

* Universidade Federal do Paraná (UFPR). Programa de Pós-Graduação em Educação. Curitiba, Paraná, Brasil. Rua: General Carneiro, nº 460. Centro. CEP: 80060-150. E-mail: suelifsol@ gmail.com; laura.ceretta@gmail.com 
na interação dialógica, entre pesquisadores e profissionais especializados, com centralidade ao protagonismo dos estudantes surdos, sujeitos da política educacional, no planejamento de ações e decisões que envolvem seu acesso e permanência na UFPR.

Palavras-chave: Educação bilíngue para surdos. Acesso e permanência no ensino superior. Letramento acadêmico bilíngue. Libras.

\begin{abstract}
The systematic enrollment of deaf students in higher education in the last decade demanded important institutional changes regarding the right to a bilingual education, that is, to provide access and production of knowledge in Brazilian sign language and in Portuguese in written form. In this sense, this article aims to discuss the process of bilingual education of deaf students in higher education, presenting actions developed within the Universidade Federal do Paraná (Federal University of Paraná, UFPR), highlighting the contributions brought to the process of bilingual academic literacy in undergraduate and post-graduate programs. We understand that the focus attributed to the figure of the interpreter of Brazilian sign language and the specialized educational service in the national policy of inclusive education does not respond to the needs of adult working deaf students who reach higher education with difficulties in reading and writing Portuguese and little significant experiences in sign language. As a positive result, we point out the contributions to the bilingual academic literacy of deaf students, the development of a specific methodology for the elaboration of bilingual material - in different textual genres - and the amplification of the translator's performance references in the inclusion process. The inclusive process consists in dialogue-based interaction between researchers and specialized professionals, with focus on the protagonism of deaf students, subjects of the educational policy, in the planning of actions and decisions that involve their access and permanence at UFPR.
\end{abstract}

Keywords: Bilingual education of deaf. Access to and permanence in higher education. Bilingual academic literacy. Libras.

\title{
Palavras iniciais sobre a política nacional de educação inclusiva: para se compreender o contexto de nossas ações
}

O reconhecimento da cidadania bilíngue da população surda brasileira, que utiliza a língua brasileira de sinais (Libras) como forma principal de co- 
municação cotidiana, foi um marco importante no cenário de políticas públicas nacionais, sobretudo no que se refere à proteção dos direitos humanos de grupos vulneráveis à exclusão e à marginalização, por diferença de cor/raça, gênero/ orientação sexual, linguística/cultural ou mesmo diferenças significativas, sejam físicas, sejam intelectuais ${ }^{1}$.

No campo da educação, a pauta reivindicatória comum que mobilizou as negociações entre movimento surdo ${ }^{2}$ e Estado, nos últimos vinte anos, é o direito de as pessoas surdas serem educadas em Libras, desde a educação infantil, e pela Língua Portuguesa - língua oficial do país - na modalidade escrita como segunda língua. Dito de outra forma, a educação bilíngue para surdos (Libras e Língua Portuguesa) é a principal bandeira de luta encampada por ativistas surdos, familiares e profissionais da área, antes e depois da oficialização da Libras no Brasil em 20023.

Apreender a educação bilíngue, como elemento norteador da política educacional para surdos, tem sido alvo de disputas e enfrentamentos, operados por posições discursivas, que expressam relações de poder assumidas pelo Ministério da Educação (MEC) em oposição ao movimento surdo, silenciando ou destacando intenções em relações aos rumos da educação de surdos no Brasil. A questão central colocada em disputa repousa no lócus preferencial da oferta da educação bilíngue que, segundo o MEC, deve ser o contexto da escola comum, ao invés de espaços exclusivos para surdos como classes e escolas bilíngues ${ }^{4}$, como defende o movimento surdo.

A crítica do movimento surdo sintetiza, a nosso ver, os limites e possibilidades de que a Libras seja a língua principal na comunicação, na mediação dos conhecimentos e na interação verbal nas integralidades das relações que envolvam estudantes surdos na escola. Para o movimento, a escola dita inclusiva cerceia o direito linguístico de valorizar sua língua minoritária, uma vez que

1 Utilizamos o conceito de "diferenças significativas" conforme utilizados por Amaral (1998, p. 13) como sinônimo de deficiência, pressuposta por "critérios, sejam eles estatísticos (moda e média), de caráter estrutural/funcional (integridade de forma/funcionamento), ou de cunho psicossocial, como o do tipo ideal".

2 O movimento surdo brasileiro está representado politicamente pela Federação Nacional de Educação e Integração dos Surdos (Feneis) e é integrado por ativistas de coletivos organizados em escolas de surdos, universidades, órgãos de classe e entidades filantrópicas.

3 Seguiu-se à Lei de Libras (Lei Federal $n^{\circ}$ 10.438/2002) diretrizes político-pedagógicas importantes, detalhadas no Decreto Federal $n^{0} 5.626 / 2005$, relativas à formação de profissionais bilíngues, à garantia de escolas e classes bilíngues como espaços específicos para a educação bilíngue para surdos, além de recomendações gerais para visibilizar e divulgar a Libras em setores da sociedade que prestam serviços essenciais e atendimento ao público.

4 Sobre esse enfrentamento ver Campello e Rezende (2014); Fernandes e Moreira (2014); Stürmer e Thoma (2015). 
a escola comum opera pelo monolinguismo em português, secundarizando ou invisibilizando a língua de sinais nas práticas discursivas.

No ensino superior, entretanto, esse embate não está posto, já que não há no cenário nacional uma alternativa de escolarização superior para surdos que não o da universidade/faculdade comum ${ }^{5}$. Os desafios que se colocam perante o processo de inclusão educacional são de outra ordem, pois demandam assegurar o direito linguístico à Libras como direito humano fundamental nas relações sociais/educacionais, em um espaço comum de aprendizagem, para estudantes surdos com perfis e competências comunicativas em Libras e Língua Portuguesa muito variados, em razão da pré-história educacional que vivenciaram promoveram, ou não, experiências de bilinguismo significativas na infância e juventude.

Também a política nacional de educação inclusiva para surdos no ensino superior é bastante ambígua em relação aos direitos linguísticos dos surdos nesta etapa de escolarização. Como se sabe, a política nacional de educação inclusiva ${ }^{6}$ prioriza a educação básica em suas diretrizes de Atendimento Educacional Especializado (AEE) para o alunado público-alvo da Educação Especial (pessoas com deficiência, transtornos globais de desenvolvimento e altas habilidades/ superdotação).

Em linhas gerais, podemos caracterizar as principais diretrizes de ação em um tripé de possibilidades: (i) a matrícula prioritária no ensino comum, (ii) a garantia de recursos de acessibilidade (urbanística, arquitetônica, nos mobiliários e equipamentos, nos transportes, na comunicação e informação) e (iii) o atendimento educacional especializado (AEE). O AEE tem como função complementar ou suplementar a formação do aluno, sendo realizado, prioritariamente, na sala de recursos multifuncionais da própria escola ou em outra escola de ensino regular, no turno inverso da escolarização, não sendo substitutivo à educação em classes comuns. (BRASIL, 2009). No caso de estudantes surdos, a educação bilíngue desenvolve o ensino escolar na Língua Portuguesa, como segunda língua na modalidade escrita, e na língua de sinais, sendo os serviços de tradutor/intérprete e o ensino da Libras para os demais estudantes da escola. (BRASIL, 2008). Vale lembrar que esse modelo tem sido difundido de forma

5 Podemos citar os Estados Unidos como exemplo de país em que há uma universidade para surdos, a Gallaudet University, instituição que usa a língua de sinais americana/inglês como meio de comunicação e que desenvolve pesquisas sobre história e cultura surdas, línguas de sinais e impactos da tecnologia na comunidade surda.

6 Embora o texto intitulado Política Nacional de Educação Especial na Perspectiva da Educação Inclusiva (BRASIL, 2008) seja reconhecido como a principal obra que demarca a política do Governo Dilma Roussef, ao nos referirmos à política nacional de educação inclusiva, estamos aludindo ao conjunto de textos que compõem o ordenamento jurídico de textos legais emanados pelo governo para fazer circular esse discurso ideológico (BRASIL, 2008, 2009, 2010, 2011). 
padronizada ao alunado público-alvo da Educação Especial com grande capilarização na educação básica dos diferentes municípios brasileiros a partir de 2008 .

No ensino superior, podemos apreender a reprodução dessa mesma lógica de atendimento nas entrelinhas dos textos legais, seja pela questão da "transversalidade da Educação Especial desde a educação infantil até a educação superior" (BRASIL, 2008, p. 10), seja pela indicação de "continuidade da escolarização nos níveis mais elevados do ensino" (BRASIL, 2008, p. 10), seja pela difusão da política "nos núcleos de acessibilidade das instituições de educação superior" (BRASIL, 2008, p. 15).

De forma explícita, entretanto, a ênfase aos recursos de acessibilidade como tônica da política de inclusão está dada neste fragmento:

Na educação superior, a educação especial se efetiva por meio de ações que promovam o acesso, a permanência e a participação dos estudantes. Estas ações envolvem o planejamento e a organização de recursos e serviços para a promoção da acessibilidade arquitetônica, nas comunicações, nos sistemas de informação, nos materiais didáticos e pedagógicos, que devem ser disponibilizados nos processos seletivos e no desenvolvimento de todas as atividades que envolvam o ensino, a pesquisa e a extensão (BRASIL, 2008, p. 12).

Do tripé anteriormente mencionado, destaca-se a matrícula no ambiente comum e o planejamento e a organização de recursos e serviços para a promoção da acessibilidade desse alunado no ensino superior. Não há menção ao AEE complementar com diretrizes para sua oferta em salas de recursos multifuncionais (tal como ocorre na educação básica).

Qual seria, desse modo, a tônica da política nacional de educação inclusiva para estudantes surdos no ensino superior? A ausência de diretrizes detalhadas para o AEE nesta etapa significaria omissão de atendimento, ou apontaria para a eliminação do atendimento complementar/suplementar? A inclusão no ensino superior estaria limitada à oferta de recursos de acessibilidade?

Neste trabalho, buscamos problematizar as limitações e as lacunas das diretrizes da atual política de inclusão, demonstrando que este modelo não se aplica efetivamente à realidade dos estudantes surdos no ensino superior. De forma complementar, discutimos ações desenvolvidas no âmbito da UFPR para promover seu acesso e permanência, com destaque às contribuições trazidas ao processo de letramento acadêmico bilíngue nos cursos de graduação e pós-graduação. 
Para explicitar as bases epistemológicas (teóricas/ideológicas) de nossa posição, apresentaremos relações entre o campo das políticas linguísticas e as políticas educacionais, como pano de fundo à consolidação de uma política de educação bilíngue no ensino superior e suas contribuições para o processo de letramento acadêmico dos estudantes surdos.

\section{Interfaces entre política linguística e política educacional na educação bilíngue para surdos: aproximações necessárias}

Como aludimos inicialmente, estudantes surdos conquistaram oficialmente o direito de utilizar, como primeira língua, uma língua diferente do português em seu processo de escolarização a partir de 2002. Esse direito linguístico constitui consenso no campo das políticas educacionais e encontra-se objetivado nos principais documentos que compõem a política nacional de Educação Especial/ Inclusiva. Destacamos o texto da Convenção sobre os Direitos das Pessoas com Deficiência (recepcionada no Brasil pelo Decreto $n^{\circ}$ 6.949/2009), sobretudo no que se refere à promoção da identidade linguística da comunidade surda ${ }^{7}$ pelo acesso e aprendizado da língua de sinais (art. 24) e o reconhecimento de uma identidade cultural e linguística específica, constituída pela língua de sinais e a cultura surda (BRASIL, 2009, art. 30, § 4).

Essa nova configuração identitária, reivindicada/atribuída aos surdos, que se edifica pelo reconhecimento da língua, da cultura e da experiência visual (STROBEL, 2008, 2009; PERLIN, 1998), em detrimento da surdez/deficiência auditiva, difunde-se nos meios intelectual e de ativismo surdos. Através de narrativas identitárias, oferecem elementos mais efetivos e consistentes para a discussão de suas necessidades no processo de inclusão educacional nas duas últimas décadas.

Em trabalho anterior, Fernandes (2011) reflete que, decorrente da concepção de sujeito, se situa o sistema político-jurídico de enquadramento de suas diferenças que redundará em um modelo institucional de educação ofertada. Nesse sentido, adotar uma nova concepção de sujeito surdo, no campo da política educacional, encaminha-se para a ruptura de práticas tradicionais que partem da avaliação do sujeito que viveu a experiência individual de deficiência auditiva/

7 Comunidade surda é aqui entendida na perspectiva definida por Nakagawa (2012, p. 31) “como um espaço de trocas simbólicas em que as línguas de sinais, a experiência visual e os artefatos culturais surdos são partilhados entre sujeitos Surdos (e ouvintes) que congregam interesses comuns e projetos coletivos". 
surdez (qual o grau de perda? É oralizado? Utiliza Aparelho de Amplificação Sonora Individual (AASI) para a proposição de uma política de inclusão que lança seu olhar às experiências coletivas/culturais da comunidade surda?).

Os intelectuais surdos Perlin e Miranda definem que o critério utilizado para identificação da "pessoa" surda tem como campo de significação a cultura surda e a utilização da visão, em (substituição total à audição), como meio de comunicação. A cultura surda é representada não apenas pelo uso da língua de sinais, mas também por um modo de se expressar, conhecer o mundo, produzir artes e conhecimento a partir da experiência visual (PERLIN; MIRANDA, 2003, p. 218).

A compreensão "comunitária", em detrimento de uma apreensão meramente individual da experiência clínico-terapêutica da deficiência auditiva, sinaliza para um indicador de organização da política de acesso e permanência no ensino superior para surdos, pois demanda ações que promovam vivências a partir de referenciais linguísticos e culturais, em detrimento de se pensar, tão somente, em aparatos e recursos tecnológicos individuais. No entanto, reconhecemos que, embora esse movimento discursivo busque difundir outras narrativas de identidades surdas e tenha ganhado espaço na produção acadêmica de conhecimento, o deslocamento no lugar ocupado pelos surdos nas relações de poder é apenas aparente.

A discursivização de uma nova concepção é necessária, mas insuficiente para uma revolução no campo da prática, em que construímos cotidianamente a materialidade de nossas ações. A despeito da visibilidade das conquistas dos movimentos surdos explicitadas na legislação, seus desdobramentos concretos em muito pouco transformaram as relações sociais e escolares, já que são predominantes nas concepções e práticas normalizadoras comuns ao território da Educação Especial (SKLIAR, 1997).

Vamos recorrer a um exemplo prático que ilustra a apropriação dessa concepção dos surdos como sujeitos linguísticos e culturais com o deslocamento aparente nas relações de poder no contexto escolar. No material veiculado pela Secretaria de Educação do Estado de São Paulo (SEESP/MEC), A Educação Especial na Perspectiva da Inclusão Escolar Abordagem Bilíngue na Escolarização de Pessoas com Surdez (ALVEZ; FERREIRA; DAMÁZIO, 2010), o AEE para surdos envolve três momentos didático-pedagógicos:

- Atendimento Educacional Especializado em Libras, que "fornece a base conceitual dos conteúdos curriculares desenvolvidos na sala de aula" e "ocorre em horário oposto ao da escolarização o professor do AEE trabalha com os conteúdos curriculares que estão sendo estudado no ensino comum em Libras, articuladamente com o professor de sala de aula" (ALVEZ; FERREIRA; DAMÁZIO, 2010, p. 12). 
- Atendimento Educacional Especializado de Libras - "ensino da Libras, por meio de métodos adequados [...] com a presença de um profissional habilitado, preferencialmente surdo, realizado em contraturno" (ALVEZ; FERREIRA; DAMÁZIO, 2010, p. 20)".

- Atendimento Educacional Especializado de Língua Portuguesa - realizado em contraturno, "no momento do AEE para o ensino da Língua Portuguesa escrita, o professor não utiliza a Libras, a qual não é indicada como intermediária nesse aprendizado" e "como o canal de comunicação específico para o ensino e a aprendizagem é a Língua Portuguesa, o aluno pode utilizar a leitura labial (caso tenha desenvolvido a habilidade) e a leitura e a escrita (ALVEZ; FERREIRA; DAMÁZIO, 2010, p. 20)”.

Sem entrar no mérito da concepção de bilinguismo adotada (praticada em contraturno e que exclui a Libras na mediação do aprendizado do português) sobre a qual temos críticas profundas (em concepção e arquitetura), observamos que este modelo atribui à Libras status de recurso de acessibilidade, a exemplo de outras tecnologias assistivas e conteúdos específicos que podem ser ofertados em contraturno, como o braile, o sorobã, a comunicação alternativa ${ }^{8}$. Da forma como se apresenta, a educação bilíngue não é programa constitutivo e integrado ao projeto político-pedagógico da escola. Quando a língua que constitui a subjetividade e a aprendizagem dos surdos está restrita a "momentos de aprendizagem" - dos quais as horas, a ela dispensadas, podem variar e depender da realidade local e cuja qualidade da interação será dependente da proficiência dos profissionais bilíngues na escola -, não estamos tratando de educação bilíngue. Este modelo também supõe que o estudante surdo disponha de atendimento em tempo integral, já que o direito à Libras, como primeira língua que "fornece a base conceitual dos conteúdos curriculares" (ALVEZ; FERREIRA; DAMÁZIO, 2010, p. 20), seria assegurada no AEE complementar.

A proposta de AEE complementar se mostra totalmente inviável ao estudante surdo adulto e trabalhador, que é o perfil que recebemos na universidade. Em um projeto de educação bilíngue efetivo, não há como imaginar que a base conceitual dos conteúdos desenvolvidos em Libras seja realizada em outro horário, senão de forma integrada às atividades em sala de aula no turno de matrícula do estudante.

O ensino de Libras, por sua vez, caracterizado ainda por lacunas de desenvolvimento de termos técnicos para as diferentes áreas de conhecimento curriculares, não pode ser objeto de ensino de "um" profissional surdo, realizado em contraturno. Primeiro, porque não há uma política pública generalizada de

8 A crítica mais aprofundada a essa concepção encontra-se publicada em Fernandes e Moreira (2014). 
concursos públicos para professores surdos nessa função, na educação básica e na superior; segundo, porque é na interação dialógica, colaborativa, viva de situações de imersão no conhecimento, envolvendo pares surdos, intérpretes e professor é que a constituição de léxico específico (sinais para termos técnicos) deve ser refletida e proposta.

O modelo do AEE, tal como proposto na política nacional, ainda opera no paradigma hegemônico da compreensão da surdez como deficiência auditiva. Essa concepção impede compreender a política linguística de educação bilíngue como pressuposto ao processo de inclusão de surdos no ensino superior.

Em contextos bilíngues, em que coexistam duas (ou mais) línguas, a variedade alta respeitada - no caso, o português -, adotada na educação formal, tende a assimilar a variedade baixa, que não goza de prestígio social, que acaba sendo relegada a situações cotidianas informais, secundarizada nas funções e usos de status social da comunidade de fala. (CALVET, 2007). Essa realidade não pode ser secundarizada em políticas inclusivas, pois extrapolam as medidas voltadas ao dito atendimento educacional especializado, e, em seu conjunto, as medidas a serem implementadas integrariam o campo da política linguística, definida por Calvet como um conjunto de decisões tomadas pelo poder público a respeito de quais línguas serão fomentadas, ensinadas ou eventualmente reprimidas e eliminadas, de quais funções as línguas terão ou deveriam ter, de quais espaços sociais ocuparão.

Desse modo, falamos de política linguística sempre que ações efetivas, no âmbito do poder público, são efetivadas para preservar e promover o direito ao uso de línguas faladas por comunidades minoritárias, como é o caso de estudantes surdos. São medidas de proteção do patrimônio cultural nacional, como também dos direitos humanos dos grupos culturais envolvidos.

$\mathrm{O}$ risco de as línguas minoritárias serem reprimidas ou eliminadas, como na análise de Calvet, situa a política linguística no campo tenso e conflituoso de relações de poder envolvendo línguas em contato, exigindo a criação de estratégias e mecanismos que permitam defender os direitos dos falantes e seus aprendizes. Esses conceitos são fundamentais para refletir sobre os cenários de escolarização básica e superior onde surdos são minoria. Geralmente o espaço concedido à Libras na escolarização é muito restrito. As interações restringem-se aos poucos membros da comunidade escolar que têm conhecimento da língua e são confinadas ao espaço de sala de aula. É comum que a Libras circule apenas na presença de tradutores e intérpretes que realizam a mediação da comunicação entre surdos e ouvintes em situações de interpretação simultânea de aulas expositivas ou eventos.

Nesse contexto, a interação verbal surdo-surdo, ou surdo-intérprete, é quase inexistente. Os surdos precisam manter contato visual com o intérprete, 
pois tomar notas no caderno, ou trocar ideias com os colegas (como é comum em sala de aula), resulta em perda da "tradução". É uma referência de aprendizagem centrada em uma postura passiva de "recepção" do conhecimento, em que dúvidas terminológicas - falta de referências conceituais prévias à compreensão do que está sendo dito - são emudecidas. O estudante surdo fica constrangido em interromper continuamente a aula, posto que não há um território conceitual dominado em português, tal como ocorre com falantes nativos. $\mathrm{O}$ esclarecimento de suas dúvidas, quase sempre muito pertinentes a quem transita na fronteira de duas línguas, é postergado a um momento posterior que nunca se realiza:

\begin{abstract}
Nesse caso, a presença do intérprete não garante ao aluno surdo o direito de negociar com o professor o significado, direito que, em tese, é garantido aos alunos ouvintes por dominarem a língua de instrução. [...] A presença do intérprete pode facilitar o cesso ao conhecimento factual para os alunos que conhecem a língua de sinais, mas não garante a construção do conhecimento conceptual, que demanda um processo de trocas discursivas entre os participantes (FAVORITO; FREIRE, 2007, p. 211).
\end{abstract}

Problematizar a restrição da função do tradutor intérprete na educação de surdos é pertinente e necessário, porque é neste profissional que tem sido depositada praticamente toda a responsabilidade do sucesso no processo de inclusão de estudantes surdos. Encarar as limitações de sua atuação nas salas de aula da educação básica e ensino superior requer o enfrentamento com medidas de intervenção para pensar a educação de surdos como uma experiência de educação bilíngue e não de um paradigma de Educação Especial, o que requer medidas de intervenção no campo da política e planificação linguística. (FAVORITO; FREIRE, 2007). Os nexos entre ações de ambos os campos políticos (política linguística e política de educação inclusiva) garantiria ações mais efetivas quanto ao direito à Libras como língua materna e, portanto, à educação bilíngue para os estudantes surdos.

O grande desafio com o qual a universidade se defronta ao receber estudantes surdos em seus quadros, não passa simplesmente por oferecer o apoio de um tradutor intérprete de Libras, como assegura a política nacional de Educação Especial, complementada pelo AEE. 


\section{Contribuições ao letramento acadêmico bilíngue de estudantes surdos na UFPR}

Nesta seção, apresentamos algumas das ações desenvolvidas no âmbito da UFPR para promover acesso e permanência dos estudantes surdos em uma perspectiva da compreensão da educação bilíngue como experiência comunitária. Além da difusão e visibilização da Libras no contexto institucional, buscamos enfatizar contribuições trazidas ao processo de letramento acadêmico bilíngue dos estudantes nos cursos de graduação e pós-graduação da UFPR.

Em um século de história da Universidade Federal do Paraná9, não há menção a um único caso de estudante surdo que utilizasse a Libras como forma principal de comunicação e que tivesse ingressado e se formado nos cursos de graduação e pós-graduação da instituição. Esse fato carrega a marca simbólica da exclusão pela diferença linguística que marginalizou gerações de surdos da participação da vida intelectual e social brasileira.

Em 2007, o Núcleo de Apoio às Pessoas com Necessidades Especiais (Napne) organizou a primeira banca especial com tradutores-intérpretes de Libras no processo seletivo do concurso vestibular, voltada especificamente a candidatos surdos que utilizam a Libras como primeira língua. A ação simbolizou uma mudança de paradigma na universidade e, desde então, houve expansão significativa na participação de candidatos surdos bilíngues no vestibular, resultando, em 2010, na aprovação da primeira candidata surda bilíngue no curso de Licenciatura em Artes, no Setor Litoral.

Apenas 100 anos depois de sua fundação, em 2012, com a aprovação de uma candidata surda no curso de Pedagogia, campus Curitiba, tem início, de fato, a política institucional bilíngue para surdos na UFPR, com apoio integral de tradutores-intérpretes de Libras no processo educacional. Entre 2008 e 2012, a UFPR sediou um polo do curso de Letras Libras - Licenciatura e Bacharelado, na modalidade EaD, promovido pela Universidade Federal de Santa Catarina (UFSC), quando participaram 30 estudantes surdos, integrados às atividades de ensino, pesquisa e extensão da universidade. O período sedimentou a oferta de cursos de Libras na comunidade e de um seminário nacional de educação de surdos da UFPR, evento bianual de comemoração ao Dia Nacional do Surdo, realizado a partir de 2010, que mobiliza a participação da comunidade surda paranaense.

9 A Universidade do Paraná foi fundada em 19 de dezembro de 1912 e federalizada em 1950, sendo reconhecida como a universidade mais antiga do Brasil. 
Com a publicização do Programa Viver sem Limite, instituído pelo Decreto $\mathrm{n}^{\mathrm{o}} 7.612 / 2011$, no Governo Dilma Rousseff, cujas diretrizes de expansão da educação bilíngue no ensino superior contemplou a UFPR com um curso presencial de Letras Libras, com vagas preferenciais para estudantes surdos. Entre 2015 e 2017, foram 49 surdos aprovados, ampliando significativamente a presença da comunidade surda na universidade. Paralelamente, houve também a expansão na pós-graduação, sobretudo no mestrado em Educação, que, entre 2013 e 2017, já formou quatro mestres surdos nas linhas de Cognição, Aprendizagem e Desenvolvimento Humano (2) e Políticas Educacionais (2).

QUADRO 1 - COMUNIDADE SURDA BILÍNGUE NA UFPR ENTRE 2010 E 2017

\begin{tabular}{|c|c|c|c|}
\hline $\begin{array}{l}\text { Ano de } \\
\text { ingresso }\end{array}$ & Número & Curso & $\begin{array}{l}\text { Língua(s) principal(is) na } \\
\text { comunicação }\end{array}$ \\
\hline 2010 & 1 & Licenciatura em Artes (Setor Litoral) & Libras/Língua Portuguesa \\
\hline 2011 & $\begin{array}{l}1 \\
1\end{array}$ & $\begin{array}{l}\text { Mestrado em Educação } \\
\text { Tecnologia em Biocombustíveis - Palotina }\end{array}$ & $\begin{array}{l}\text { Libras/Língua Portuguesa } \\
\text { Libras/Língua Portuguesa }\end{array}$ \\
\hline 2012 & 1 & Pedagogia & Libras/Língua Portuguesa \\
\hline 2013 & 1 & Mestrado em Educação & Libras/Língua Portuguesa \\
\hline 2014 & $\begin{array}{l}3 \\
7\end{array}$ & $\begin{array}{l}\text { Mestrado em Educação } \\
\text { Professores surdos letras Libras }\end{array}$ & $\begin{array}{l}\text { Libras } \\
\text { Libras }\end{array}$ \\
\hline 2015 & $\begin{array}{l}22 \\
01\end{array}$ & $\begin{array}{l}\text { Letras Libras } \\
\text { Mestrado em Educação }\end{array}$ & Libras \\
\hline 2016 & $\begin{array}{l}14 \\
01 \\
01\end{array}$ & $\begin{array}{l}\text { Letras Libras } \\
\text { Lic. Computação - Campus Jandaia do Sul } \\
\text { Professor Surdo Letras Libras* } \\
\text { Mestrado em Educação }\end{array}$ & $\begin{array}{l}\text { Libras/Língua Portuguesa } \\
\text { Libras/Língua Portuguesa } \\
\text { Libras/Língua Portuguesa } \\
\text { Libras/Língua Portuguesa }\end{array}$ \\
\hline 2017 & $\begin{array}{l}12 \\
01 \\
01 \\
01\end{array}$ & $\begin{array}{l}\text { Letras Libras } \\
\text { Matemática } \\
\text { Mestrado em Educação } \\
\text { Mestrado em Ciência Matemática }\end{array}$ & $\begin{array}{l}\text { Libras/Língua Portuguesa } \\
\text { Libras } \\
\text { Libras/Língua Portuguesa } \\
\text { Libras/Língua Portuguesa }\end{array}$ \\
\hline Total & 70 & & \\
\hline
\end{tabular}

FONTE: autoras (2017) com base nas matrículas oficiais da Universidade Federal do Paraná. PróReitoria de Graduação e Educação Profissional, Napne (2017).

* Concurso público com vagas do Programa Viver sem Limite (BRASIL, 2011).

Essa presença, detalhada em números e cursos no Quadro 1, redesenhou as ações e medidas de acesso, ingresso e permanência implementadas para dar resposta às necessidades linguísticas específicas desses estudantes sinalizantes da Libras na UFPR. Como se sabe, a geração de estudantes surdos que conclui o ensino médio nos anos 2000 vivenciou a transição de um sistema educacional que invisibilizava (ou, até mesmo, proibia) a língua de sinais para a incorporação da Libras nas práticas escolares. 
Baseado em pesquisa de Fernandes (2014), apontamos que as dificuldades e lacunas no processo de alfabetização/letramento de estudantes surdos que concluem o ensino médio com domínio elementar da leitura e escrita em português, sem a vivência em gêneros textuais científicos, que costumam circular no ensino superior, como resumos, artigos, resenhas, dissertações, entre outros. Soma-se a esse fato, a fluência limitada, em sua própria língua de identificação, pela falta de oportunidade de ter vivenciado experiências de interlocução significativas em Libras nos campos da política, da literatura, da arte, das ciências exatas. Ou seja, a Libras não se constituiu língua de cultura ao longo da educação básica, a exemplo do que acontece com as línguas orais no processo educacional.

Sabemos que, no Brasil, são inúmeras as ações desenvolvidas para a inclusão de estudantes surdos em diferentes universidades brasileiras, sobretudo a partir da implantação dos cursos de Letras Libras ${ }^{10}$ presenciais e na modalidade de EaD, das políticas de acesso e permanência de sujeitos com deficiência na educação superior do Programa de Acessibilidade na Educação Superior (Incluir), com destaque à criação e ao fortalecimento dos Núcleos de Acessibilidade nas instituições de ensino superior. Todas as experiências são expressão de limitações e singularidades da trajetória de cada instituição e de concepções de sujeito e educação de surdos subjacentes ao seu projeto político-pedagógico.

No caso da UFPR, as ações empreendidas, sobretudo, a partir de 2012, quando a presença da comunidade surda na universidade se fez mais marcante, são exígua planificação de uma política de educação bilíngue para surdos, centrada no fortalecimento e visibilidade da Libras, não apenas nos espaços reservados à sala de aula. Nesse sentido, compreendemos que o processo de letramento acadêmico bilíngue dos estudantes deve ser um alvo a ser perseguido, de modo a proporcionar a vivência em práticas discursivas que envolvam gêneros textuais que costumam circular na esfera acadêmica.

A noção de gênero discursivo/textual vem sendo incorporada aos estudos da linguística aplicada, sobretudo na área de metodologia de ensino de Língua Portuguesa, desde os anos 1990, e pode ser definida como:

[...] uma noção propositalmente vaga para referir os textos materializados que encontramos em nossa vida diária e que apresentam características sociocomunicativas definidas por conteúdos, propriedades funcionais, estilo e composição característica (MARCUSCHI, 2003, p. 22).

10 A publicação "Letras Libras - ontem, hoje e amanhã" (QUADROS, 2015) traz um relato detalhado das importantes ações de visibilização da Libras nas IFES, a partir da criação dos cursos de Letras Libras (Licenciatura e Bacharelado), na modalidade de EaD, promovido pela UFSC, a partir de 2006. 
Souza e Bassetto (2014) argumentam que a participação ativa e efetiva, no meio acadêmico, exige manejar as convenções comunicativas/pragmáticas dessa comunidade discursiva, ou seja, ser capaz de ler/compreender e produzir os gêneros textuais como editais, provas, resumos, artigos, fichamentos, monografias etc. O letramento no ensino superior envolve múltiplos desafios aos estudantes surdos que utilizam o português como segunda língua, já que seu processo de aproximação com gêneros textuais acadêmicos costuma causar estranhamento pelos usos da linguagem, do conhecimento técnico veiculado como conteúdo, da ausência de repertório lexical em Libras para sinalizar equivalentes na Língua Portuguesa, pela falta de experiência de interações verbais nessa esfera discursiva, pela complexidade dos conteúdos envolvidos nesse campo epistemológico.

Nossa hipótese é que a superação dessas dificuldades passaria pela vivência de práticas de leitura e escrita também acessíveis em Libras. Dentre os gêneros textuais acadêmicos que passaram a circular em Libras na UFPR estão os editais de prova e de concurso, a prova bilíngue do vestibular, os materiais de apoio como textos-base das disciplinas (artigos e capítulos de livros) traduzidos para videolibras.

FIGURA 1 - EDITAIS EM LIBRAS

CONCURSO PÚBLICO EDITAL No 38/17 -PROGEPE Linguística/Ensino da Libras e Educação Bilíngue para Surdos

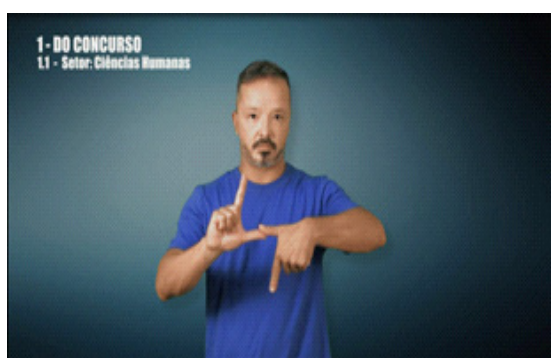

FONTE: Universidade Federal do Paraná, Pró-Reitoria de Gestão de Pessoas (2017).
EDITAL No 25/2016 - NC/UFPR - PROCESSO SELETIVO DO CURSO DE LICENCIATURA EM LETRAS LIBRAS
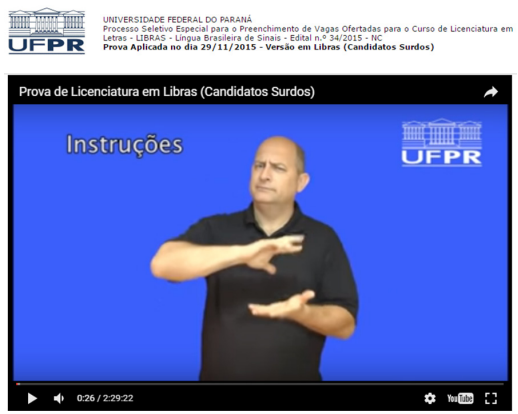

FONTE: Universidade Federal do Paraná (2016).

Além dos editais sinalizados (Figura 1), a primeira fase do processo de seleção do mestrado e doutorado faculta aos candidatos surdos o apoio de tradutores-intérpretes de Libras e a possibilidade de realização de prova bilíngue (Libras e Português). As provas realizadas em Libras são registradas em vídeo e traduzidas para a Língua Portuguesa. A banca avaliadora tem acesso apenas 
ao áudio da tradução da leitura da prova em Libras, já que o processo seletivo não prevê identificação das provas dos candidatos nesta fase.

Além dos editais, na correção das provas escritas dos candidatos surdos bilíngues, são adotados critérios de avaliação coerentes com sua condição de aprendiz de português como segunda língua, sobretudo quanto à qualidade linguística do texto, valorizando o aspecto semântico (conteúdo) e reconhecendo a singularidade linguística manifestada no aspecto formal, decorrente de possível influência da estrutura da Libras.

No processo vestibular bilíngue do curso de licenciatura em Letras Libras, modalidade presencial, foi atribuída à Libras status de língua principal na mediação do processo de avaliação, como ação afirmativa de política linguística no ensino superior, pela UFPR.

A prova compõe-se de 30 questões, sendo 20 questões objetivas de múltipla escolha, com os enunciados disponibilizados apenas em Libras, sobre Conhecimentos Gerais e Específicos; 9 questões objetivas de português como segunda língua, disponibilizadas apenas em Língua Portuguesa e 1 questão discursiva. $\mathrm{O}$ caderno de provas possui instruções em português na folha de rosto, traduzidas integralmente para a Libras (Figura 2), contemplando nossa discussão inicial de expor o candidato ao gênero textual "instrução", de forma bilíngue.

\section{FIGURA 2 - GÊNERO TEXTUAL: INSTRUÇÕES (PORTUGUÊS E LIBRAS)}

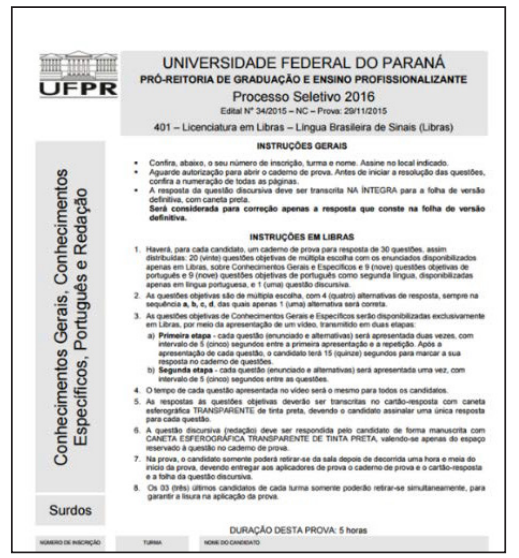

\section{Gênero: Instruções da Prova}

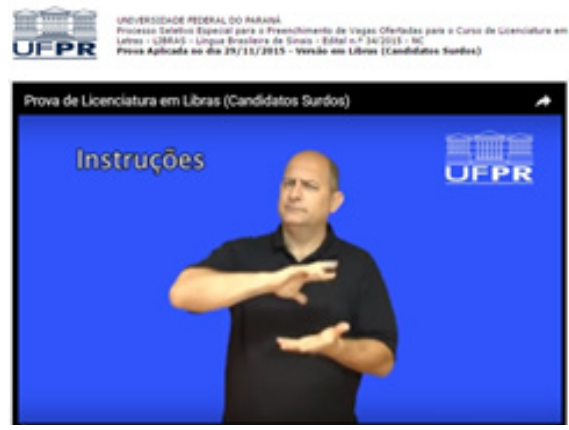

FONTE: Universidade Federal do Paraná, Núcleo de Concursos (2017).

A organização da prova em videolibras requer uma metodologia de produção específica, baseada em uma concepção de letramento que dá centralidade à experiência visual no processo de apropriação de conhecimento pelos estudantes 
surdos. Partimos da premissa de que a Libras é a língua de mediação no processo seletivo que mobilizará a experiência da "leitura" do texto sinalizado, tal qual ocorre com a Língua Portuguesa para os demais candidatos em um processo seletivo que tem um caderno de provas escrito.

Temos desenvolvido estudos sobre o letramento de Fernandes (2003, 2006, 2014) que comprovam que sujeitos surdos estabelecem com o texto uma relação de natureza essencialmente visual, cuja internalização de sentidos depende da mediação da Libras. A língua de sinais, como linguagem verbal de modalidade visual-espacial, produzida historicamente no seio das comunidades surdas, atua como conteúdo sígnico mediador no processo de apropriação (internalização) dos meios externos do desenvolvimento cultural do pensamento humano (VYGOTSKY, 1991).

Ancorada nesses pressupostos, a metodologia de produção das provas e de tradução dos materiais didáticos está sempre contextualizada em referenciais visuais compostos de linguagem verbal (Libras e legendas em português para termos técnicos) e não verbal (fotos, desenhos, esquemas, símbolos etc.), de modo a potencializar associações, inferências e reflexões para a constituição dos sentidos do texto.

Em razão disso, empreendemos três elementos na semiose visual do texto (palavra sinalizada + palavra escrita + imagem) como princípio de formulação das questões em Libras, conforme pode se observar em alguns exemplos das provas de conhecimentos gerais e específicos ilustrados na Figura 3.

\section{FIGURA 3 - GÊNERO TEXTUAL: PROVA EM LIBRAS}
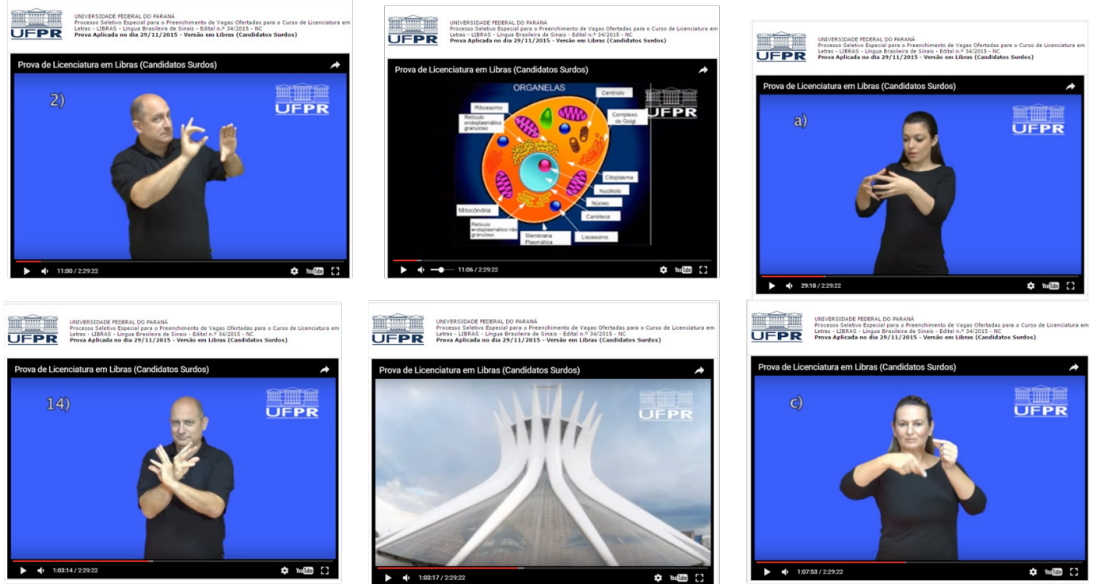

FONTE: Universidade Federal do Paraná, Núcleo de Concursos (2017). 
Considerando que os textos articulam linguagem verbal e não verbal na constituição de sentidos e mobilizam nossa experiência social prévia, essa leitura ancorada em referências imagéticas (verbais e não verbais) é que estará na base das práticas de letramento acadêmico bilíngue para surdos.

O fato de a prova avaliar, principalmente a competência comunicativa da compreensão em Libras, as questões objetivas de conhecimentos gerais (10) e específicos (10) são disponibilizadas em duas etapas: na primeira etapa, cada questão (enunciado e alternativas) é apresentada duas vezes, com intervalo de cinco segundos entre a primeira apresentação e a repetição. Após a apresentação de cada questão, o candidato tem quinze segundos para marcar a sua resposta no caderno de questões; na segunda etapa, cada questão (enunciado e alternativas) é apresentada uma vez, com intervalo de cinco segundos entre as questões. Em razão dessa dinâmica requerer do candidato um esforço de memorização visual para captar o comando global da questão, buscamos elaborar o caderno de provas, de modo a complementar informações e detalhes específicos que, por nervosismo, ou outro fator, sejam esquecidos pelo candidato, impedindo a resolução da questão.

Assim, reiteramos o princípio de associação entre linguagem verbal e não verbal, mantendo gráficos, infográficos, imagens, esquemas, tabelas e outros elementos no caderno de provas. Essas informações tranquilizam o candidato ao saber que poderão ser retomados mais detidamente para a resolução da questão, mesmo após o término da projeção (Figura 4). Julgamos ser esse um princípio de equidade em relação a candidatos que realizam provas escritas e podem manusear os dados presentes no texto reiteradas vezes durante o período de realização da prova.

\section{FIGURA 4 - GÊNERO TEXTUAL: CADERNO DE PROVAS}
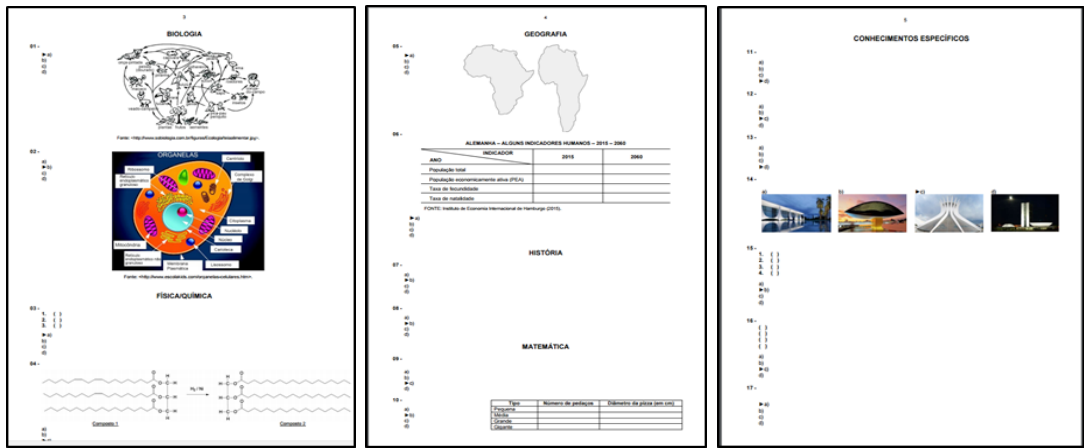

FONTE: Universidade Federal do Paraná, Núcleo de Concursos (2017). 
Os mesmos pressupostos anunciados na metodologia de produção da videoprova em Libras são estendidos à prova de português como segunda língua (L2). As questões pontuam especificamente a compreensão e a interpretação de textos e, em algumas delas, buscamos contemplar a linguagem não verbal como elemento complementar à leitura do texto (Figura 5).

\section{FIGURA 5 -GÊNERO TEXTUAL: PROVA DE PORTUGUÊS COMO SEGUNDA LÍNGUA}
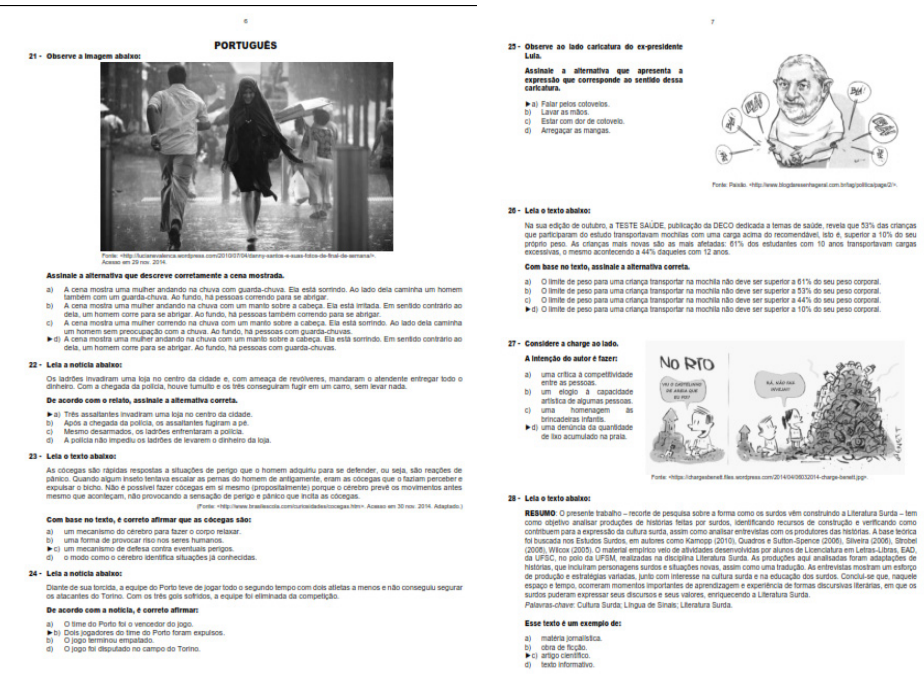

FONTE: Universidade Federal do Paraná, Núcleo de Concursos (2017).

Essa demonstrou ser uma decisão acertada, já que em estudo comparativo do número de acertos obtidos entre os surdos, na prova aplicada no processo seletivo do ano de 2014 (Tabela 1), observamos que o índice de acertos entre os candidatos surdos ultrapassou $70 \%$ nas questões com imagem $(21,25$ e 27$)$ e permaneceram entre 30 e $40 \%$ nas questões exclusivamente com texto escrito. Os resultados contribuem para o aprimoramento desse processo, com respostas mais efetivas à natureza do letramento visual, característico dos candidatos surdos. 
TABELA 1 - COMPARATIVO DO NÚMERO DE ACERTOS DE QUESTÕES COM E SEM IMAGEM DA PROVA DE PORTUGUÊS COMO L2

\begin{tabular}{|c|c|c|c|}
\hline Número da questão & Presença de imagem & $\begin{array}{c}\text { Acertos (de um } \\
\text { total de 46) }\end{array}$ & $\begin{array}{c}\text { Índice de acertos } \\
\mathbf{( \% )}\end{array}$ \\
\hline $\mathbf{2 1}$ & Sim & 35 & 76,09 \\
\hline $\mathbf{2 2}$ & Não & 25 & 54,35 \\
\hline $\mathbf{2 3}$ & Não & 20 & 43,48 \\
\hline $\mathbf{2 4}$ & Não & 25 & 54,35 \\
\hline $\mathbf{2 5}$ & Sim & 35 & 76,09 \\
\hline $\mathbf{2 6}$ & Não & 21 & 45,65 \\
\hline $\mathbf{2 7}$ & Sim & 35 & 76,09 \\
\hline $\mathbf{2 8}$ & Não & 18 & 39,13 \\
\hline $\mathbf{2 9}$ & Não & 13 & 28,26 \\
\hline
\end{tabular}

FONTE: autoras (2017).

Por fim, relatamos a experiência na atuação dos tradutores-intérpretes para propiciar a acessibilidade linguística aos estudantes surdos no ensino superior, por meio da tradução de textos acadêmicos registrados em vídeos (hipervídeos).

Fernandes, Medeiros e Lemos (2015) refletem que a prática da tradução de textos escritos para a Libras é um campo de estudos recente que amplia os referenciais de atuação do intérprete (geralmente restritos à interpretação simultânea em sala de aula), aprimorando sua competência tradutória e qualificando o acesso ao conhecimento pelos estudantes surdos. Para os autores, o acesso a textos acadêmicos em Libras permite a acessibilidade linguística no espaço universitário e promove seu letramento em Libras e Língua Portuguesa, colocando os estudantes surdos em equidade com os demais estudantes ouvintes.

Para realizar os hipervídeos (Figura 6) na UFPR, a equipe de tradutores-intérpretes da UFPR utilizou as normas técnicas da Revista Brasileira de Vídeo Registros em Libras, desenvolvidas pela UFSC, que é uma revista digital que visa à sistematização, consolidação e divulgação de produções acadêmicas em Libras, observando as características de uma língua visual-espacial (MARQUES; OLIVEIRA, 2012).

Importante também destacar nesse processo o trabalho colaborativo envolvendo a equipe de professores surdos, especialistas da área, tradutores e intérpretes de Libras, e, principalmente, a escuta das necessidades e demandas da tradução de textos apontadas pelos estudantes e professores surdos da UFPR. 


\section{FIGURA 6 - EXEMPLOS DE TRADUÇÃO DE TEXTOS ACADÊMICOS TRA- DUZIDOS EM LIBRAS}

Sinalário em Libras da UFPR

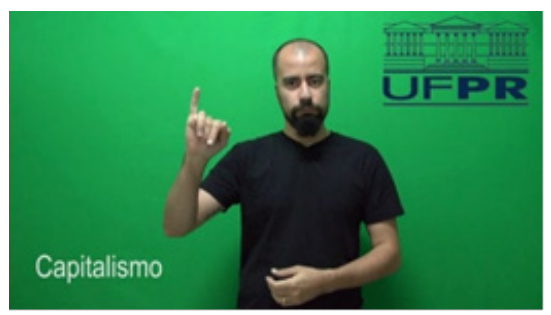

FONTE: Fernandes, Medeiros e Lemos (2015).
Recursos semióticos e de legenda utilizados na tradução

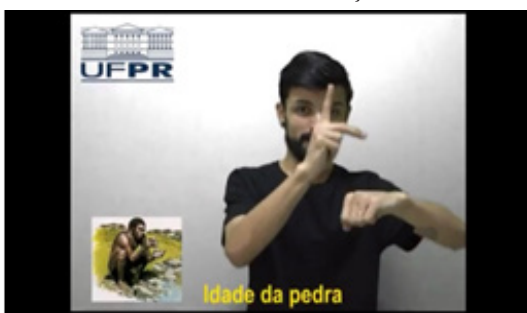

\section{Considerações finais}

Neste estudo, buscamos pontuar alguns dos desafios inerentes ao processo de educação inclusiva de estudantes surdos no ensino superior, relatando nossa experiência na UFPR.

Nossa crítica à centralidade atribuída à figura do tradutor-intérprete de Libras e ao AEE diz respeito a esse modelo não atender às necessidades dos estudantes surdos adultos que chegam ao ensino superior. Contudo, propõe uma nova forma de abordagem e intervenção centrada em medidas de política linguística de educação bilíngue como pressupostos ao processo de inclusão de surdos no ensino superior.

Acreditamos que ações de acesso e permanência no ensino superior devem ter como elemento norteador a construção de uma proposta de educação bilíngue comunitária, envolvendo todos os membros da comunidade universitária. A visibilidade da Libras na universidade, promovendo sua circulação em gêneros textuais diversos, desde editais de concursos e vestibulares até provas e textos de apoio às disciplinas, são parte desse processo de constituição da Libras como língua de cultura no ensino superior e valorização da comunidade surda na UFPR.

Estabelecer novas relações de poder, nos espaços de negociação entre Libras e português, passa pela visibilização da língua de sinais como língua que produz conhecimento e cultura nos canais de informação da universidade, nas práticas discursivas em sala de aula e outros espaços.

Como resultados positivos das políticas de acesso e permanência, apontamos as contribuições ao letramento acadêmico bilíngue de estudantes surdos, o desenvolvimento de metodologia específica para elaboração de materiais bilín- 
gues, em diferentes gêneros textuais, a ampliação dos referenciais de atuação do tradutor-intérprete no processo de inclusão.

Todo esse processo deve partir da interação dialógica entre pesquisadores e profissionais especializados e do protagonismo dos estudantes surdos, sujeitos da política educacional, no planejamento de ações e decisões que envolvem seu acesso e permanência na UFPR.

\section{REFERÊNCIAS}

ALVEZ, C. B.; FERREIRA, J. P.; DAMÁZIO, M. M. A Educação Especial na perspectiva da inclusão escolar. Abordagem bilíngue na escolarização de pessoas com surdez. Brasília: Universidade Federal do Ceará; MEC/SEESP, 2010.

AMARAL, L. A. Sobre crocodilos e avestruzes: falando de diferenças físicas, preconceitos e sua superação. In: AQUINO, J. G. (org.). Diferenças e preconceito na escola: alternativas teóricas e práticas. 5. ed. São Paulo: Summus, 1998. p. 11-30.

BRASIL. Lei n ${ }^{\circ}$ 10.436, de 24 de abril de 2002. Dispõe sobre a Língua Brasileira de Sinais (LIBRAS) e dá outras providências. Disponível em: <http://www.planalto.gov. br/ccivil_03/LEIS/2002/L10436.htm>. Acesso em: 15 fev. 2017.

BRASIL. Decreto $n^{\circ} 5.626$, de 22 de dezembro de 2005. Regulamenta a Lei no 10.436 , de 24 de abril de 2002, que dispõe sobre a Língua Brasileira de Sinais - Libras. Disponível em: <http://www.planalto.gov.br/ccivil_03/_ato2004-2006/2005/decreto/d5626.htm>. Acesso em: 15 fev. 2017.

BRASIL. Decreto $\mathrm{n}^{\circ}$ 6.571, de 17 de setembro de 2008. Dispõe sobre o atendimento educacional especializado, regulamenta o parágrafo único do art. 60 da Lei $\mathrm{n}^{\circ} 9.394$, de 20 de dezembro de 1996, e acrescenta dispositivo ao Decreto ${ }^{\circ} 6.253$, de 13 de novembro de 2007. Diário Oficial da União, Brasília: MEC/SEESP, 18 set. 2008a.

BRASIL. Ministério da Educação. Secretaria de Educação Especial. Política Nacional de Educação Especial na Perspectiva da Educação Inclusiva. Brasília: MEC/SEESP, $2008 \mathrm{~b}$. Disponível em: $<$ http://peei.mec.gov.br/arquivos/politica_nacional_educacao_especial. pdf>. Acesso em: 10 fev. 2017.

BRASIL. Resolução $n^{\circ} 04$, de 02 de outubro de 2009. Diretrizes Operacionais para o Atendimento Educacional Especializado na Educação Básica, modalidade Educação Especial. Brasília: MEC/SEESP, 2009a. Disponível em: <http://portal.mec.gov.br/ dmdocuments/rceb004_09.pdf >. Acesso em: 17 fev. 2017. 
BRASIL. Decreto Federal $n^{\circ}$ 6.949, de 25 de agosto de 2009. Convenção sobre os Direitos das Pessoas com Deficiência. Brasília: Secretaria de Direitos Humanos, Secretaria Nacional de Promoção dos Direitos da Pessoa com Deficiência, 2009b.

BRASIL. Ministério da Educação. Secretaria de Educação Continuada, Alfabetização, Diversidade e Inclusão. Programa de Implantação de Salas de Recursos Multifuncionais. São Paulo: Secretaria de Educação Especial - MEC/SEESP, 2010.

BRASIL. Decreto n ${ }^{\circ} 7612 / 2011$. Institui o Plano Nacional da Pessoa com Deficiência - Plano Viver sem Limites. 17 de novembro de 2011. Brasília: Distrito Federal, 2011.

CALVET, L.-J. As politicas linguísticas. São Paulo: Parábola; Florianópolis: IPOL, 2007. $168 \mathrm{p}$.

CAMPELLO, A. R.; REZENDE, P. L. F. Em defesa da escola bilíngue para surdos: a história de lutas do movimento surdo brasileiro. Educar em Revista, Curitiba, edição especial 2, p. 71-92, 2014.

FERNANDES, S. Educação bilingue para surdos: identidades, diferenças, contradições e mistérios. Tese (Doutorado em Letras) - Setor de Ciências Humanas, Universidade Federal do Paraná, Curitiba. 2003. Disponível em: <http://acervodigital.ufpr.br/bitstream/ handle/1884/24287/T\%20-\%20FERNANDES,\%20SUELI\%20DE\%20FATIMA\%20. pdf?sequence $=1>$. Acesso em: 11 jan. 2017.

FERNANDES, S. Letramentos na educação bilíngue para surdos. In: BERBERIAN, A. P.; MASSI, G.; DE ANGELIS, C. C. M. Letramento: referências em saúde e educação. Plexus, 2006.

FERNANDES, S. Políticas linguísticas e de identidade(s): a língua como fator de (in) exclusão dos surdos. Revista Trama, Cascavel, v. 7, p. 109-123, 2011.

FERNANDES, S. Avaliação escolar e educação bilíngue para surdos: a questão das línguas na política de inclusão. In: ALMEIDA, M. A.; MENDES, E. G. (Org.). A escola e o público-alvo da Educação Especial: apontamentos atuais. Marília: ABPEE Marquezine \& Manzini, v. 1, p. 141-158, 2014.

FERNANDES, S.; MOREIRA, L. C. Políticas de educação bilíngue para surdos: o contexto brasileiro. Educar em Revista, Curitiba, v. 2, p. 51-69, 2014.

FERNANDES, S.; MEDEIROS, J.; LEMOS, R. A tradução Libras/Língua Portuguesa: uma contribuição para a inclusão de estudantes surdos do ensino superior na UFPR. In: CONGRESSO NACIONAL DE EDUCAÇÃO - EDUCERE, 12, 2015, Curitiba. Anais: Formação de professores, complexidade e trabalho docente, 2015. v. 1. p. 2417-2428.

FAVORITO, W.; FREIRE, A. M. F. Relações de poder e saber na sala de aula: contextos de interação com alunos surdos. In: COUTO, M. C.; BORTONI-RICARDO, S. M. (Org.). Transculturalidade, linguagem e educação. Vol. 1. Campinas: Mercado de Letras, 2007. p. 7-252. 
MARCUSCHI, L. A. Gêneros textuais: definição e funcionalidade. In: DIONÍSIO, A. P.; MACHADO, A. R.; BEZERRA, M. A. (Orgs.). Gêneros textuais e ensino. 2. ed. Rio de Janeiro: Lucerna, 2003.

MARQUES, R. R.; OLIVEIRA, J. S. A normatização de artigos acadêmicos em Libras e sua relevância como instrumento de constituição de corpus de referência para tradutores. In: CONGRESSO NACIONAL DE PESQUISAS EM TRADUÇÃO E INTERPRETAÇÃO DE LIBRAS E LÍNGUA PORTUGUESA, 3, 2012. Anais... Disponível em: $<$ http:// www.congressotils.com.br/anais/anais/tils2012_metodologias_traducao_marquesoliveira.pdf>. Acesso: 20 fev. 2017.

NAKAGAWA, H. E. Culturas surdas: o que se vê, o que se ouve. Tese (Doutorado em Letras) - Faculdade de Letras, Universidade de Lisboa, Lisboa, 2012. Disponível em: $<$ https://repositorio.ul.pt/handle/10451/8801>. Acesso em: 27 fev. 2017.

PERLIN, G.; MIRANDA, W. Surdos: o Narrar e a Política In: Estudos Surdos, Ponto de Vista. Revista de Educação e Processos Inclusivos, UFSC/ NUP/CED, Florianópolis, n. $5,2003$.

PERLIN. G. Identidades Surdas. In: SKLIAR, C. A surdez: um olhar sobre as diferenças. Porto Alegre: Mediação, 1998.

QUADROS, R. M. Letras Libras: ontem, hoje e amanhã. Florianópolis: UFSC, 2015.

SKLIAR, C. (org.). Educação e exclusão: abordagens socioantropológicas em Educação Especial. Porto Alegre: Mediação, 1997.

SOUZA, M. G. de; BASSETTO, L. M. T. Os processos de apropriação de gêneros acadêmicos (escritos) por graduandos em letras e as possíveis implicações para a formação de professores/pesquisadores. Rev. Bras. Linguist. Apl., Belo Horizonte, v. 14, n. 1, p. 83-110, mar. 2014. Disponível em: $<$ http://www.scielo.br/scielo.php?script=sci arttext\&pid=S1984-63982014000100005\&lng=en\&nrm=iso $>$. Acesso em: 26 fev. 2017.

STROBEL, K. L. Surdos: vestígios culturais não registrados na História. Tese (Doutorado em Educação) - Universidade Federal de Santa Catarina, Florianópolis. 2008.

STROBEL, K. L. As imagens do outro sobre a cultura surda. Florianópolis, UFSC, 2009.

STÜRMER, I. E.; THOMA, A. da S. Políticas Educacionais e Linguísticas para Surdos: discursos que produzem a educação bilíngue no Brasil na atualidade. In: REUNIÃO ANUAL DAASSOCIAÇÃO NACIONAL DE PÓS-GRADUAÇÃO E PESQUISA EM EDUCAÇÃO (ANPEd), 37, 2015. Anais... Florianópolis, 2015. p. 1-15. Disponível em: $<$ http://37reuniao.anped.org.br/wp-content/uploads/2015/02/Trabalho-GT15-4093.pdf $>$. Acesso em: 26 fev. 2017.

UNIVERSIDADE FEDERAL DO PARANÁ (UFPR). Curso de licenciatura em letras-Libras. 2016. Disponível em: <http://www.nc.ufpr.br/concursos_institucionais/ libras/2017/libras_ed_25.htm>.Acesso em: 15 dez. 2016. 
UNIVERSIDADE FEDERAL DO PARANÁ (UFPR). Pró-Reitoria de Graduação e Educação Profissional. Núcleo de Apoio às Pessoas com Necessidades Especiais (NAPNE). Alunos com necessidades educacionais especiais. Relatório. Curitiba, 2017.

UNIVERSIDADE FEDERAL DO PARANÁ (UFPR). Núcleo de Concursos. 2017. Disponível em: <http://www.nc.ufpr.br/>. Acesso em: 17 jan. 2017.

UNIVERSIDADE FEDERAL DO PARANÁ (UFPR). Programa de Pós-Graduação em Educação. Mestrado e doutorado. 2017. Disponível em: <http://www.ppge.ufpr.br/>. Acesso em: 16 dez. 2017.

UNIVERSIDADE FEDERAL DO PARANÁ (UFPR). Pró-Reitoria de Gestão de Pessoas. Concursos para a carreira de docentes da UFPR. 2017. Disponível em: $<\mathrm{http}: / /$ www.progepe.ufpr.br/progepe/concursos/docente/concursos_publicos/concursos.html>. Acesso em: 10 jan. 2017.

VYGOTSKI, L. S. A formação social da mente. 4. ed. São Paulo: Martins Fontes, 1991.

Texto recebido em 05 de março de 2017. Texto aprovado em 20 de março de 2017. 